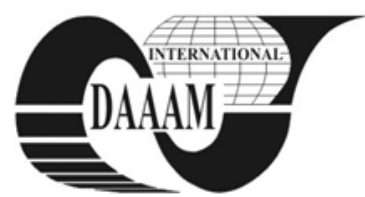

Annals of DAAAM for 2011 \& Proceedings of the 22nd International DAAAM Symposium, Volume 22, No. 1, ISSN 1726-9679 ISBN 978-3-901509-83-4, Editor B. Katalinic, Published by DAAAM International, Vienna, Austria, EU, 2011 Make Harmony between Technology and Nature, and Your Mind will Fly Free as a Bird

\title{
THE EFFECT OF THERMAL TENSION ON QUALITY MILL ROLLS
}

\author{
JOSAN, A[na]; PINCA - BRETOTEAN, C[amelia] \& RATIU, S[orin] A[urel]
}

\begin{abstract}
The paper presents simulation of hot rolling process of profile I, to determine the state of tension in the rolling cylinders, using professional simulation software COSMOS / M 2.5. Initial data from the simulation program (the application of cooling water and rolled pieces temperatures) are data taken in Romanian industrial companies. The simulation is performed for two cases of rolling: the application of cooling water on two and four surfaces at a temperature of $800^{\circ} \mathrm{C}, 850^{\circ} \mathrm{C}$ respectively. Recorded values are presented for thermal stress in the two cases of simulation, thermal stress inducing the thermal fatigue (this influencing durability cylinders rolling operation).

Key words: cylinder, temperature, numerical simulation, durability
\end{abstract}

\section{INTRODUCTION}

A most actual issue of the metallurgical enterprises is the low durability in exploitation of the lamination cylinders, these being the most stressed parts of the rolling mill assembly cages.

The rolling mill cylinders work in hot conditions, with complex variable stress, due to lamination process, repeated at regular time periods. In general, the lamination cylinders are calculated taking into account only the static forces action (constant in time), condition only partial satisfactory in operation. If the study of the cylinder resistance is continued to their durability, then we have to take into account the whole complex of stresses, with mechanical-thermal influences.

The casing of the lamination cylinder's calibration works under complex conditions, as (Josan, 2005; Masek et al., 2010):

- bending tension, produced by the lamination forces;

- torsion tension, produced by the lamination moments;

- tension due to contact pressure, which is produced in the area of the distortion focal point (mechanical tensions);

- thermal tensions, produced by the temperature variations in the lamination cylinders, which, on one side, are getting hotter, being in contact with the burning laminate and, on the other side, being cooled with water jets. The cooling of the cylinders, during the lamination process, can be done in two points (positions) or, by optimizing the process, in four points. The temperature of the laminate can vary between $800 \ldots 850^{\circ} \mathrm{C}$.

The total action of the above mentioned tensions is specific to the operation process of the hot lamination cylinders.

Following the study of the thermal areas at hot lamination, we can say that, in the lamination cylinders there are present some temperature distributions which produce cyclic unitary thermal stresses at each rotation of the lamination cylinder, generating the thermal fatigue of the superficial layer of the lamination calibers (Toader \& Pinca C, 1996)

\section{CALCULATION OF THE THERMAL TENSION EFFECTS, IN THE SITUATION OF WATER COOLING ON TWO SURFACES, AT $800^{\circ} \mathrm{C}$}

In order to understand the reason used in the calculation of the tension status due to unitary thermal forces and the results after simulation, it is necessary to present some details of the spatial stress status. In this general tension status, on the surfaces of an isolated element, around one random point of the solid part, we can meet all components of the stress, directed parallel with the axis of a reference system OXYZ (fig.1) (Grigorescu et al., 2010; Josan, 2005; Toader \& Pinca C, 1996).

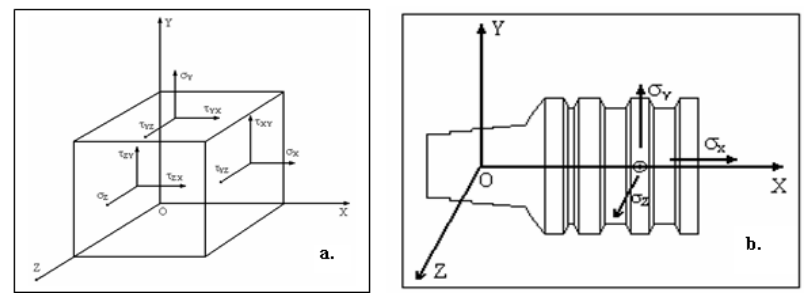

Fig. 1. Space of tension status, where $\sigma_{X}, \sigma_{Y}, \sigma_{Z}$ is normal tensions, and $\tau_{\mathrm{XY}}, \tau_{\mathrm{ZY}}, \tau_{\mathrm{YX}}, \tau_{\mathrm{ZX}}, \tau_{\mathrm{XZ}}, \tau_{\mathrm{YZ}}$, are tangent tensions: a) general case; $b$ ) particular case (lamination cylinder)

In the case of making the calculation of the thermal tensions at $800^{\circ} \mathrm{C}$, with the cooling of the lamination cylinders on two surfaces, it has been taken into consideration that the tensions in the axles' area are not relevant (Josan, 2005). After running the simulation program the values of the tensions $\sigma_{X}$, $\sigma_{Y}$, and $\sigma_{Z}$ are presented (fig. 2,3,4,5). Tab.1 presents the values (max and $\min$ ) of tensions registered for this case.

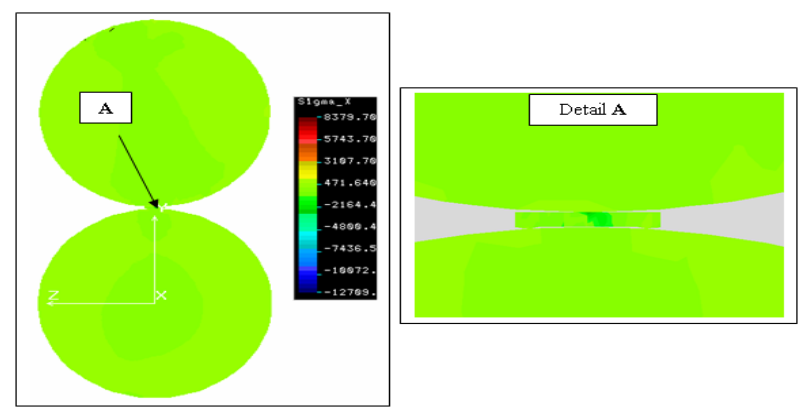

Fig. 2. The tensions $\sigma_{\mathrm{X}}$ recorded in cross sections

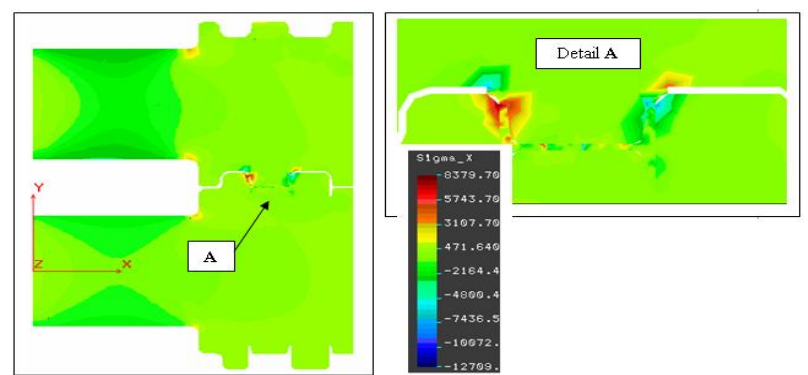

Fig. 3. The tensions $\sigma_{\mathrm{X}}$ recorded in longitudinal sections

\begin{tabular}{|c|c|c|c|}
\hline Tensions, $\mathrm{N} / \mathrm{mm}^{2}$ & $\sigma_{\mathrm{X}}$ & $\sigma_{\mathrm{Y}}$ & $\sigma_{\mathrm{Z}}$ \\
\hline Max. & 8379,70 & 4047,00 & 3034,50 \\
\hline Min. & -12709 & $-3873,2$ & $-6038,7$ \\
\hline
\end{tabular}

Tab. 1. Tensions values registered $\left(\right.$ at $\left.800^{\circ} \mathrm{C}\right)$ 


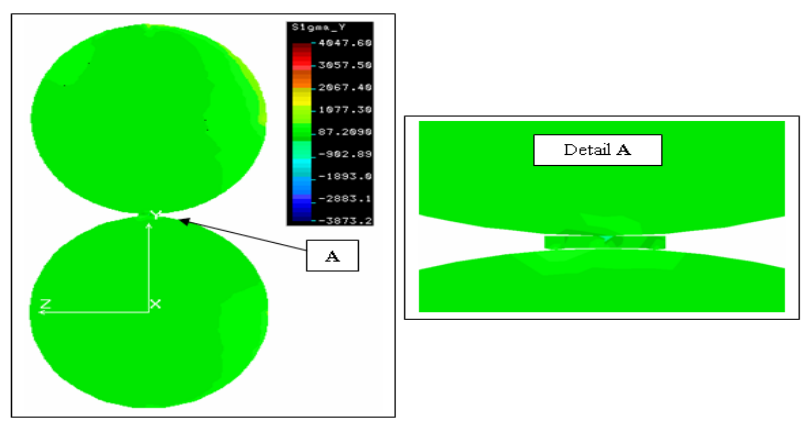

Fig. 4. The tensions $\sigma_{\mathrm{Y}}$ recorded in cross sections.

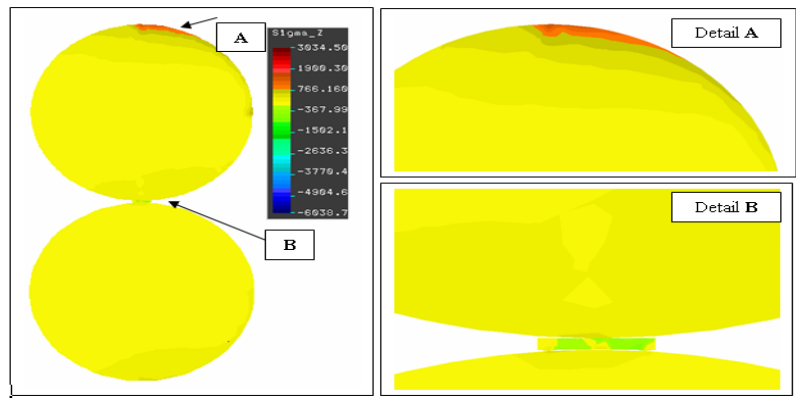

Fig. 5. The tensions $\sigma_{\mathrm{Z}}$ recorded in cross sections.

From the above figures we can see that the tensions recorded $\sigma_{\mathrm{Y}}$ and $\sigma_{\mathrm{Z}}$ are almost constant section (temperature gradient is not high).

\section{CALCULATION OF THE EFFECTS OF THE THERMAL TENSIONS, IN THE CASE OF THE WATER COOLING ON FOUR SURFACES, AT $850^{\circ} \mathrm{C}$}

Similarly, in the case of the calculation of the thermal tensions at $850^{\circ} \mathrm{C}$, with the cooling of the lamination cylinders on four surfaces, it has been taken into consideration the fact that the tensions in the axle's area are not relevant. So, in longitudinal section is taken into account tensions along the three axes $\sigma_{\mathrm{X}}, \sigma_{\mathrm{Y}}$, $\sigma_{\mathrm{Z}}$ (fig. 6,7,8). Tab. 2 presents the values of tensions registered for the case studied.

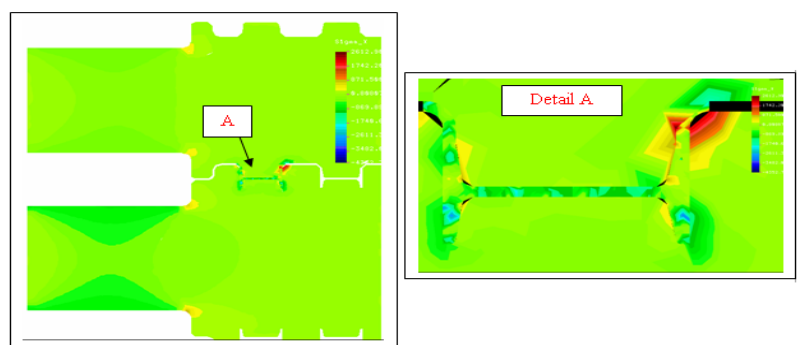

Fig. 6. The tensions $\sigma_{X}$ recorded in longitudinal sections.

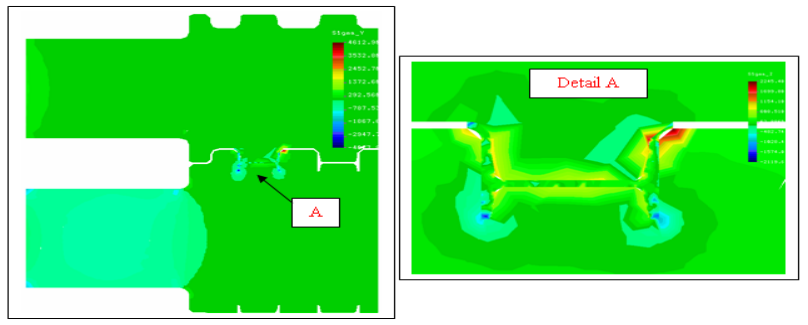

Fig. 7. The tensions $\sigma_{Y}$ recorded in longitudinal sections.

\begin{tabular}{|c|c|c|c|}
\hline Tension, N/mm & $\sigma_{\mathrm{X}}$ & $\sigma_{\mathrm{Y}}$ & $\sigma_{\mathrm{Z}}$ \\
\hline Max. & 2612,90 & 4692,90 & 2245,40 \\
\hline Min. & $-4352,70$ & $-4027,80$ & $-2149,80$ \\
\hline
\end{tabular}

Tab. 2. Tensions values registered (at $850^{\circ} \mathrm{C}$ )

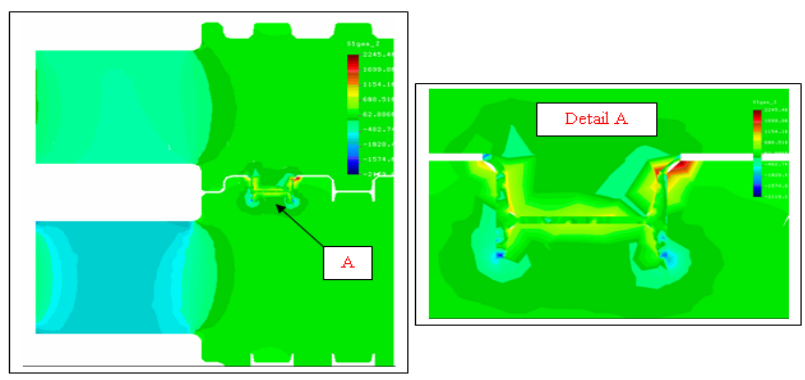

Fig. 8. The tensions $\sigma_{\mathrm{Z}}$ recorded in longitudinal sections.

\section{CONCLUSIONS}

Following the analysis of the complex phenomena which appear in the cylinders during the hot lamination process, we can assess that the lamination cylinders can stand over complex variable stress as a result of overlapping the thermal tensions over the mechanical ones. So, we can take the following conclusions: 1.the precise knowledge of the condition of the tensions generated by complex stress over hot lamination cylinders allows the calculation of their operation lifetime, in safe conditions, by comparing with foreseen limit values;

2.thermal tensions are the fundamental cause of producing cracks on the lamination cylinder surface, due to thermal stress;

3.the lamination cylinders are broken in the operation process due to their thermal weariness;

Performed to simulate hot rolling process were obtained the following results:

1) The simulation of the hot lamination process of the profile I has been effected, comparatively, for both cooling methods (on two and four surfaces) and for temperatures of 800 and $850^{\circ} \mathrm{C}$;

2) For actual operation conditions, the simulation of the process supplied very high values in the situation where the cooling water is on two points and the laminate has a temperature of $800^{\circ} \mathrm{C}$, this being the most adverse situation. In the case where the cooling water is applied on four points (optimal), even with a laminate with higher temperature, respectively $850^{\circ} \mathrm{C}$, the tensions $\sigma_{\mathrm{Y}}$ and $\sigma_{\mathrm{Z}}$ have approximately the same values, but the recorded value for the tension $\sigma_{\mathrm{x}}$ decreased with approx. $30 \%$.

3) The thermal tensions have a crucial role in determining a higher value of durability recorded in operation. To avoid high value thermal tensions (which induce thermal weariness and ex-foiling) is recommended the use of water cooling on four surfaces.

4) Simulation can be applied to other types of cylinders (of different shapes and sizes) to avoid cracks on the surface or other machine parts working under similar conditions.

\section{REFERENCES}

Comaneci, R. (2009). A Comparative Study of Severe Plastic Deformation Techniques by Finite Element Analysis, Annals of DAAAM for 2009 \& Proceedings of the 20th International DAAAM Symposium, 25-28th November 2009, Vienna, Austria, ISSN 1726-9679, ISBN 978-3-901509-70-4, Katalinic, B. (Ed.), pp. 0879-0880, Published by DAAAM International Vienna, Vienna

Josan, A. (2005). The durability of mill rolls cast Adamit steel, Publishing Mirton, ISBN 973-661-564-2, Timisoara

Grigorescu, C.; M.; Moraru, S.; A. \& Badea, M. (2010). Smart Data Acquisition Software Used in Industrial Monitoring Systems, Annals of DAAAM for 2010 \& Proceedings of the 21 st International DAAAM Symposium, 20-23rd October 2010, Zadar, Croatia, ISSN 1726-9679, ISBN 978-3-901509-73-5, Katalinic, B. (Ed.), pp. 0103-0104, Published by DAAAM International Vienna, Vienna

Masek, B.; Jirkova, H.; Malina, J. \& Klauberova, D. (2010). The Material-Technological Modeling of the Real Dynamic Process, Annals of DAAAM for 2010 \& Proceedings of the 21st International DAAAM Symposium, 20-23rd October 2010, Zadar, Croatia, ISSN 1726-9679, ISBN 978-3-901509-73-5, Katalinic, B. (Ed.), pp. 0169-0170, Published by DAAAM International Vienna, Vienna

Toader Ş.; Pinca C (1996). Researches regarding the thermal fatigue of the hot mill rolls, Contract research no.7004/1996, Theme 4, CNCSIS 